\title{
Endobronchial Coils for Endoscopic Lung Volume Reduction: Best Practice Recommendations from an Expert Panel
}

\author{
Dirk-Jan Slebos ${ }^{a, b}$ Nick H. ten Hacken ${ }^{a, b}$ Martin Hetzel ${ }^{c}$ Felix J.F. Herth ${ }^{d}$ \\ Pallav L. Shah ${ }^{\mathrm{e}-\mathrm{g}}$ \\ a Department of Pulmonary Diseases, University of Groningen, University Medical Center Groningen (UMCG), \\ Groningen, The Netherlands; ${ }^{\mathrm{b}}$ Groningen Research Institute for Asthma and COPD, University of Groningen, \\ University Medical Center Groningen (UMCG), Groningen, The Netherlands; ' Krankenhaus vom Roten Kreuz, \\ Stuttgart, Germany; ${ }^{\mathrm{d}}$ Thoraxklinik and Translational Lung Research Center (TLRC), University of Heidelberg, \\ Heidelberg, Germany; ${ }^{e}$ Royal Brompton and Harefield NHS Foundation Trust, London, UK; ${ }^{f}$ Chelsea and \\ Westminster Hospital NHS Foundation Trust, London, UK; 9 National Heart and Lung Institute, Imperial College, \\ London, UK
}

\section{Keywords}

Endobronchial coils · Endoscopic lung volume reduction ·

Severe emphysema · COPD · Bronchoscopy

\begin{abstract}
Endobronchial coils are an additional treatment option for lung volume reduction in patients with severe emphysema. Patient selection should be focused on patients with severe emphysema on optimal medical therapy and with evidence of severe hyperinflation. The technique is suitable in a broad range of patients with emphysema; however, patients with paraseptal emphysema, large focal (giant) bullae, significant co-morbidity and airway-predominant disease should be avoided. Treatment involves placing between 10 and 14 coils by bronchoscopy in the selected treatment lobe, with 2 lobes being treated sequentially. Lobe selection for treatment should be based on quantitative computed tomography, and the lobes with the greatest destruction should be targeted (excluding the right middle lobe). The treatment results in an improvement in pulmonary function, exercise
\end{abstract}

performance and quality of life, particularly in patients with severe hyperinflation (residual volume $>200 \%$ predicted) and upper-lobe heterogeneous emphysema, but will also be of benefit in lower-lobe predominant and homogeneous emphysema. Finally, it has an acceptable safety profile, although special attention has to be paid to coil-associated opacity which is an inflammatory response that occurs in some patients treated with endobronchial coils.

(c) 2018 The Author(s)

Published by S. Karger AG, Basel

Previous articles in this series: 1. Shah PL, Herth FJF: Progress in Interventional Pulmonology. Respiration 2018;95:287-288. 2. Bonta PI, Chanez P, Annema JT, Shah PL, Niven R: Bronchial Thermoplasty in Severe Asthma: Best Practice Recommendations from an Expert Panel. Respiration 2018;95:289-300. 3. Colella S, Haentschel M, Shah P, Poletti V, Hetzel J: Transbronchial Lung Cryobiopsy in Interstitial Lung Diseases: Best Practice. Respiration 2018;95:383-391. 4. Gompelmann D, Shah PL, Valipour A, Herth FJF: Bronchoscopic Thermal Vapor Ablation: Best Practice Recommendations from an Expert Panel on Endoscopic Lung Volume Reduction. Respiration 2018:95:392-400.

\begin{tabular}{|c|c|}
\hline KARGER & $\begin{array}{l}\text { (c) } 2018 \text { The Author(s) } \\
\text { Published by S. Karger AG, Basel }\end{array}$ \\
\hline $\begin{array}{l}\text { E-Mail karger@karger.com } \\
\text { www.karger.com/res }\end{array}$ & $\begin{array}{l}\text { This article is licensed under the Creative Commons Attribution- } \\
\text { NonCommercial-NoDerivatives } 4.0 \text { International License (CC BY- } \\
\text { NC-ND) (http://www.karger.com/Services/OpenAccessLicense). } \\
\text { Usage and distribution for commercial purposes as well as any dis- } \\
\text { tribution of modified material requires written permission. }\end{array}$ \\
\hline
\end{tabular}

Dirk-Jan Slebos, $\mathrm{MD}, \mathrm{PhD}$

Department of Pulmonary Diseases, AA11

University Medical Center Groningen

PO Box 30001, NL-9700 RB Groningen (The Netherlands)

E-Mail d.j.slebos@umcg.nl 


\section{Introduction}

Endoscopic lung volume reduction is a realistic treatment option for selected patients with severe emphysema $[1,2]$. Different endoscopic lung volume reduction approaches have been developed to accommodate the different emphysema phenotypes, with both endobronchial oneway valve treatment and endobronchial coil treatment being the most intensively investigated [3-6]. These therapies are also recognised in the recent chronic obstructive pulmonary disease (COPD) GOLD recommendations [7]. The endobronchial coils are "non-blocking" devices which are delivered by bronchoscopy into the sub-segmental airways. Unlike one-way endobronchial valves, the endobronchial coils are also effective in patients with interlobar collateral ventilation and, thus, work independent of this phenomenon. Furthermore, endobronchial coils do not induce lobar atelectasis and, hence, cause minimal reduction on the gas exchange area of the treated lobe. The coils are made from shape memory nitinol (a nickel-titanium alloy) wire (Fig. 1). About 10-14 coils are placed at each treatment under fluoroscopic guidance, with the objective of treating 2 contralateral lobes in 2 separate procedures, with the contralateral lobe being treated $4-8$ weeks later. The procedure is preferably performed under general anaesthesia, and the patients are hospitalized for at least 1 night for observation after the procedure. However, this can vary widely with local practice. This article provides detailed guidance by an international panel of experts experienced in this therapy regarding patient selection, peri-procedural care and technical guidance on performing the procedure. We have also addressed the management of procedural complications.

\section{Summary of Clinical Evidence}

Early feasibility studies and randomized clinical trials have shown consistent benefits with improvements in pulmonary function, quality of life and 6-minute walking distance test for treated patients in comparison with control patients who received optimal medical management of their emphysema. Table 1 provides an overview of the most relevant endobronchial coil trials published [8-17].

\section{Mechanisms of Action}

Understanding the mechanisms of action is important, as this may facilitate better patient selection, enable optimization of the implantation technique and drive the de-

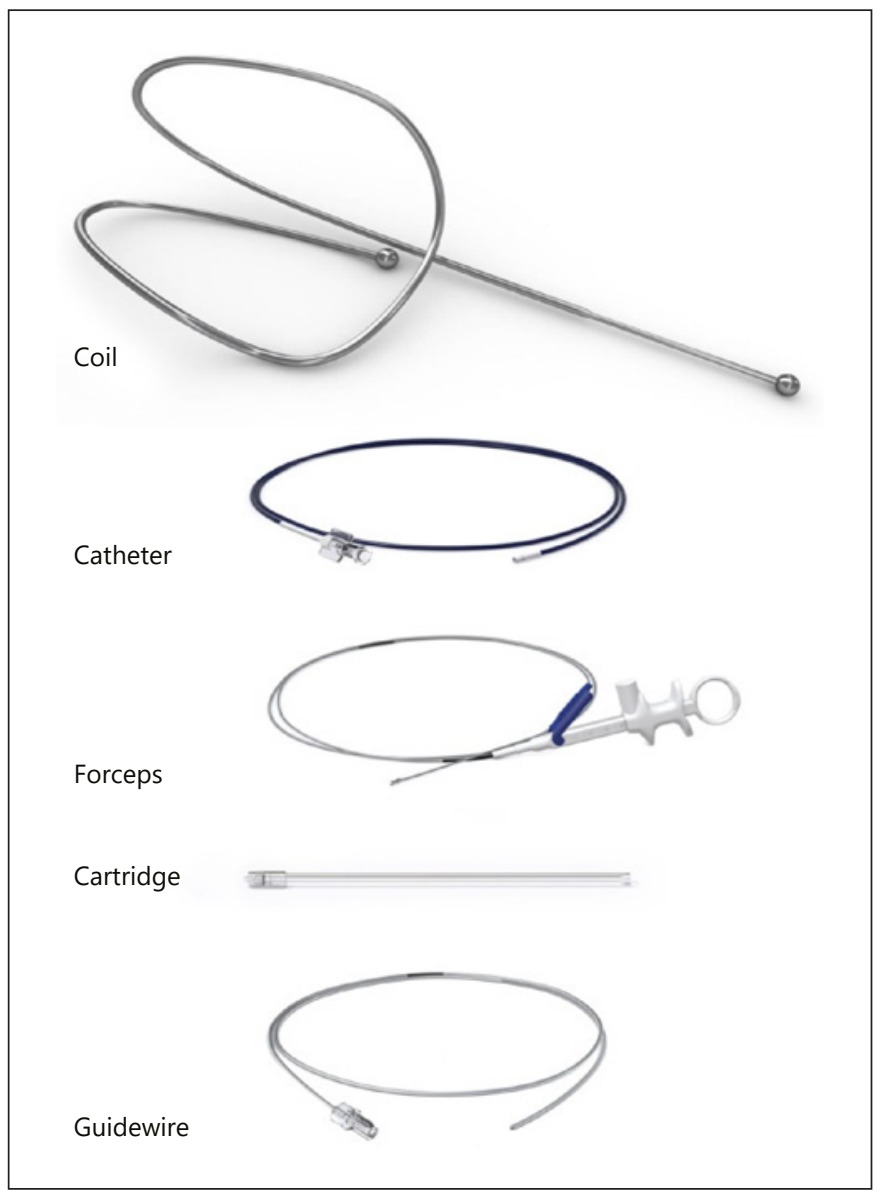

Fig. 1. The PneumRx endobronchial coil system. The system consists of a single-patient use delivery system with a cartridge, catheter, guidewire, forceps and coils (with permission from Pneum$\mathrm{Rx}, \mathrm{CA}, \mathrm{USA})$. The coil is available in 3 lengths (100, 125 and 150 $\mathrm{mm}$ ) to accommodate the different airways. The distal and proximal ends of the coil are designed to reside in sub-segmental airways.

velopment of new coils, perhaps even adjusted to the individual needs and characteristics of a patient. Differing views exist, and one possibility is that the nitinol wires, following deployment, return to their predetermined shape, distorting the airways and thereby compressing the diseased tissue and achieving re-tensioning of the diseased airway network to decrease air-trapping and hyperinflation. Additionally, improved elastic recoil and hyperinflation are thought to improve diaphragm and inspiratory muscle function [18]. Finally, well-placed coils may theoretically improve elastic recoil forces locally and, thus, reduce overall inhomogeneity of ventilation. Unfortunately, no study has so far systematically investigated these different mechanisms of action. One computed tomography 
Table 1. Studies on lung volume reduction coil treatment for emphysema

\begin{tabular}{|c|c|c|c|c|c|c|c|}
\hline $\begin{array}{l}\text { First author [ref.], } \\
\text { year }\end{array}$ & Design & Patients & Follow-up & $\triangle \mathrm{FEV} 1$ & $\Delta \mathrm{RV}$ & $\triangle 6 \mathrm{MWD}$ & $\triangle \mathrm{SGRQ}$ \\
\hline \multicolumn{8}{|c|}{ Non-controlled studies } \\
\hline $\begin{array}{l}\text { Slebos [9], } \\
2012\end{array}$ & pilot & $\begin{array}{l}16 \\
\text { hetero }\end{array}$ & $\begin{array}{l}3 \text { months } \\
6 \text { months }\end{array}$ & $\begin{array}{l}19.9 \pm 20.0 \% \\
14.9 \pm 17.0 \%\end{array}$ & $\begin{array}{l}-11.1 \pm 9.9 \% \\
-11.4 \pm 9.0 \%\end{array}$ & $\begin{array}{l}62.2 \pm 76.6 \mathrm{~m} \\
84.4 \pm 73.4 \mathrm{~m}\end{array}$ & $\begin{array}{l}-12.6 \pm 10.8 \\
-14.9 \pm 12.1\end{array}$ \\
\hline $\begin{array}{l}\text { Klooster [13], } \\
2014\end{array}$ & $\begin{array}{l}\text { prospective, } \\
\text { open label }\end{array}$ & $\begin{array}{l}10 \\
\text { hetero }\end{array}$ & $3-4$ months & $\begin{array}{l}16.6 \% \\
(-16 \text { to } 55)\end{array}$ & $\begin{array}{l}-0.79 \mathrm{~L} \\
(-1.20 \text { to } 0.04)\end{array}$ & $\begin{array}{l}42 \mathrm{~m} \\
(15 \pm 141)\end{array}$ & $\begin{array}{l}-11 \\
(-25 \pm 6)\end{array}$ \\
\hline $\begin{array}{l}\text { Konto- } \\
\text { gianni [12], } \\
2014\end{array}$ & retrospective & $\begin{array}{l}26 \\
\text { hetero }\end{array}$ & $\begin{array}{l}90 \text { days } \\
180 \text { days }\end{array}$ & $\begin{array}{l}0.10 \pm 0.13 \mathrm{~L} \\
0.04 \pm 0.12 \mathrm{~L}\end{array}$ & $\begin{array}{l}-0.60 \mathrm{~L} \\
-0.42 \mathrm{~L}\end{array}$ & $\begin{array}{l}47 \pm 54 \mathrm{~m} \\
32 \pm 60 \mathrm{~m}\end{array}$ & $\begin{array}{l}-7 \\
-6\end{array}$ \\
\hline \multicolumn{8}{|c|}{ Controlled studies using a usual care group } \\
\hline $\begin{array}{l}\text { Shah }[10] \\
2013\end{array}$ & $\begin{array}{l}\text { RCT } \\
\text { parallel }\end{array}$ & $\begin{array}{l}23 \text { vs. } 23 \\
\text { mixed }\end{array}$ & 90 days & $\begin{array}{l}14.2 \% \\
(6.8 \text { to } 21.6)\end{array}$ & $\begin{array}{l}-0.51 \mathrm{~L} \\
(-0.73 \text { to }-0.30)\end{array}$ & $\begin{array}{l}51.2 \mathrm{~m} \\
(27.7-74.4)\end{array}$ & $\begin{array}{l}-8.1 \\
(-13.8 \text { to } 2.4)\end{array}$ \\
\hline $\begin{array}{l}\text { Deslee [17], } \\
2016\end{array}$ & $\begin{array}{l}\mathrm{RCT} \\
\text { parallel }\end{array}$ & $\begin{array}{l}50 \text { vs. } 50 \\
\text { mixed }\end{array}$ & 1 year & $\begin{array}{l}8 \% \\
\text { (CI } 3 \text { to } 13)\end{array}$ & $\begin{array}{l}-9 \% \\
(\mathrm{CI}-12 \text { to }-5)\end{array}$ & $\begin{array}{l}-0.05 \% \\
(\mathrm{CI}-10 \text { to } 10)\end{array}$ & $\begin{array}{l}-9.1 \\
(\mathrm{CI}-14.1 \text { to }-4.2)\end{array}$ \\
\hline $\begin{array}{l}\text { Zoumot [8], } \\
2015\end{array}$ & $\begin{array}{l}\text { RCT } \\
\text { cross-over }\end{array}$ & $\begin{array}{l}23 \text { vs. } 22 \\
\text { mixed }\end{array}$ & $\begin{array}{l}90 \text { days } \\
180 \text { days } \\
360 \text { days }\end{array}$ & $\begin{array}{l}13.8 \pm 18.1 \% \\
10.0 \pm 21.1 \% \\
8.9 \pm 22.2 \%\end{array}$ & $\begin{array}{l}-7.1 \pm 10.5 \% \\
-5.8 \pm 13.6 \% \\
-5.4 \pm 13.7 \%\end{array}$ & $\begin{array}{l}20.3 \pm 23.8 \% \\
20.2 \pm 20.8 \% \\
14.0 \pm 20.8 \%\end{array}$ & $\begin{array}{l}-4.7 \pm 13.4 \\
-7.3 \pm 12.2 \\
-6.1 \pm 14.0\end{array}$ \\
\hline $\begin{array}{l}\text { Sciurba [11], } \\
2016\end{array}$ & $\begin{array}{l}\text { RCT } \\
\text { parallel }\end{array}$ & $\begin{array}{l}158 \text { vs. } 157 \\
\text { mixed }\end{array}$ & 12 months & $\begin{array}{l}3.8 \% \\
(\mathrm{CI}-6.3 \text { to } 16.1)\end{array}$ & $\begin{array}{l}-0.41 \mathrm{~L} \\
(\mathrm{CI} 0.57 \text { to }-0.25)\end{array}$ & $\begin{array}{l}10.3 \mathrm{~m} \\
(\mathrm{CI}-33.0 \text { to } 45.0)\end{array}$ & $\begin{array}{l}-8.1 \\
(\mathrm{CI}-10.2 \text { to }-6.0)\end{array}$ \\
\hline
\end{tabular}

Values are changes from baseline with \pm standard deviation or range or 95\% CI in parentheses. Between-group differences for coil versus usual care (in the RCTs) are not shown. RCT, randomized controlled trial; FEV1, forced expiratory volume in the first second; RV, residual volume; 6MWD, 6-minute walking distance; SGRQ, St George's Respiratory Questionnaire Response; hetero, heterogeneous distribution of emphysema; mixed, heterogeneous and homogeneous emphysema; CI, confidence interval.

(CT) scan study measured in- and expiratory lobe volumes and luminal areas of segmental bronchi, before and after coil treatment, in 30 severe emphysema patients [19]. In the treated segmental bronchia, the cross-sectional lumen decreased significantly during inspiration and tended to increase during expiration. Volumes of the treated segments correlated with the treated segmental bronchial lumina in expiration $(r=0.80, p<0.001)$. The authors suggest that the data of the study are in support of the current understanding of coil effects, which claim that they stabilise and stiffen the lung parenchyma, thus compensating for the loss of elasticity in the lung interstitium and consequently reducing bronchial motility and collapsing. A further study by Palamidas et al. [20] evaluated lobar volumes in a randomised controlled study. Target lobar volumes were decreased, and compensatory hyperinflation of the untreated ipsilateral lobes was observed. Hence, there was no dramatic reduction in total lung capacity (TLC). There were strong correlations between reduction in volumes of the treated lobes and changes in pulmonary function. The greatest effects appeared to occur in patients who developed inflammatory coil-associated opacities. This inflammatory process itself induces localised fibrosis and, hence, volume reduction with improvements in pulmonary function.

\section{Patient Selection}

Patient selection is a critical and very important part of the treatment for attaining the best outcomes. Important selection criteria include the following: 


\section{Spirometry and Hyperinflation}

The key parameters are evidence of severe airflow obstruction (forced expiratory volume in the first second $\left[\mathrm{FEV}_{1}\right] \leq 45 \%$ predicted) and the presence of severe hyperinflation. For this treatment modality, hyperinflation should be measured by body plethysmography. Patients with a residual volume $(\mathrm{RV})>200 \%$ predicted are deemed the best responders. In some situations, patients with an

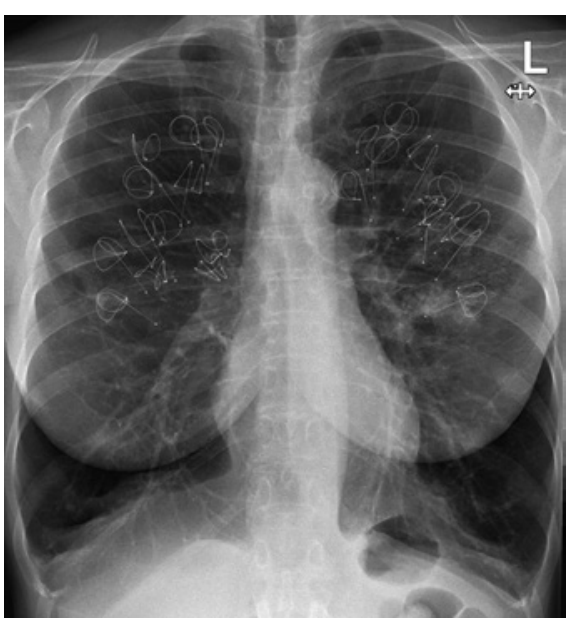

Fig. 2. Coils implanted in homogeneous emphysema. Chest X-ray in a patient with homogeneous emphysema and severe hyperinflation. Twelve coils have been implanted in the right upper lobe and 10 in the left upper lobe. The distribution of the coils is around the upper part of the hilum, keeping enough distance to the pleurae. A small coil-associated opacity is seen around the most inferiorly located coil on the left side.
RV between 175 and 200\% predicted may be considered for treatment if other measures of hyperinflation are favourable, i.e., $\mathrm{RV} / \mathrm{TLC}$ ratio $\geq 0.58[21,22]$.

\section{Symptoms and Exercise Performance}

Patients should be highly symptomatic with respect to dyspnoea (modified British Medical Research Council $[\mathrm{mMRC}]>1)$ and restricted in their exercise performance (6-minute walking distance $<450 \mathrm{~m}$ ). However, if a patient has significant symptoms of concurrent chronic airways disease, such as frequent cough, severe bronchial hyper-responsiveness, sputum production and/or frequent exacerbations, the patient should not be considered for coil treatment. Also, patients with a very low exercise tolerance (6-minute walking distance $<140 \mathrm{~m}$ ) may not represent the ideal candidates for therapy.

\section{Emphysema Morphology}

Centrilobular to moderate panlobular emphysema is the best emphysema phenotype for coil treatment. Severe panlobular emphysema, giant bullae and paraseptal emphysema are morphological patterns of emphysema that are not suitable for treatment with endobronchial coils. Computerised quantitative CT analysis using densitometry should be utilised to more accurately assess the amount of parenchymal destruction and guide optimal selection of the treatment site. Potential sites of treatment are where there is lobar destruction of $20-80 \%$ at the -950 HU threshold on a low (or "soft") kernel reconstructed thin-slice $(1 \mathrm{~mm})$ high-resolution CT. The lobes with the greatest degree of destruction should be targeted. Endobronchial coils can be used independent of collateral ven-

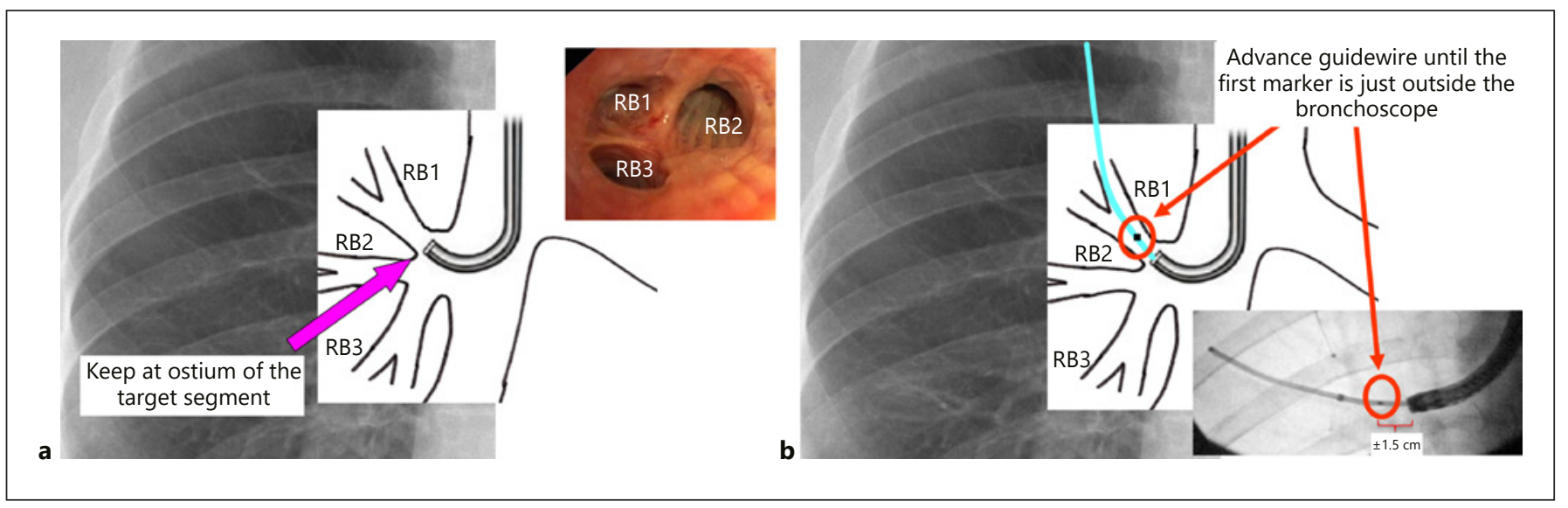

Fig. 3. Optimal position of the bronchoscope and guidewire. a The bronchoscope is placed at the ostium of the target segment in a fixated manner. $\mathbf{b}$ The guidewire is advanced until the first marker is just outside the bronchoscope. In this position, mostly a coil of $125 \mathrm{~mm}$ can be placed in the target area of the lung (see Fig. 4). 
tilation, and, hence, fissure integrity is not a crucial assessment. However, the authors recommend a more holistic approach when assessing patients and would recommend a full evaluation followed by a multi-disciplinary discussion to ensure that the patient receives the best treatment option for their individual situation [4]. Furthermore, emphysema patients with both a homogeneous or heterogeneous emphysema distribution can be treated. Similarly, both upper lobe or lower lobe emphysema may be treated.

\section{Coil Placement}

The Lung Volume Reduction Coil System

The PneumRx endobronchial coil system (Pneum$\mathrm{Rx}, \mathrm{CA}, \mathrm{USA}$ ) is a two-part system consisting of coils and a delivery system (Fig. 1). The delivery system comprises a guidewire, a delivery catheter, locking grasping forceps and a loading cartridge. The forceps are used to grasp and fixate the proximal end of the coil, which is then pulled into the loading cartridge. The loading cartridge is slid over the forceps and the coil is effectively straightened when it is pulled into the cartridge. Coils are composed of nitinol, a biocompatible super-elastic material that is shaped in a special pre-determined double loop. The distal and proximal ends of the coil are terminated with a smooth atraumatic ball. The coil is available in 3 lengths $(100,125$ and $150 \mathrm{~mm})$ to accommodate different-sized airways. A coil is delivered straight into an airway and switches back to its pre-determined shape upon deployment. The tools require a therapeutic bronchoscope with a minimum $2.8-\mathrm{mm}$ working channel.

Box 1. Key points in patient selection

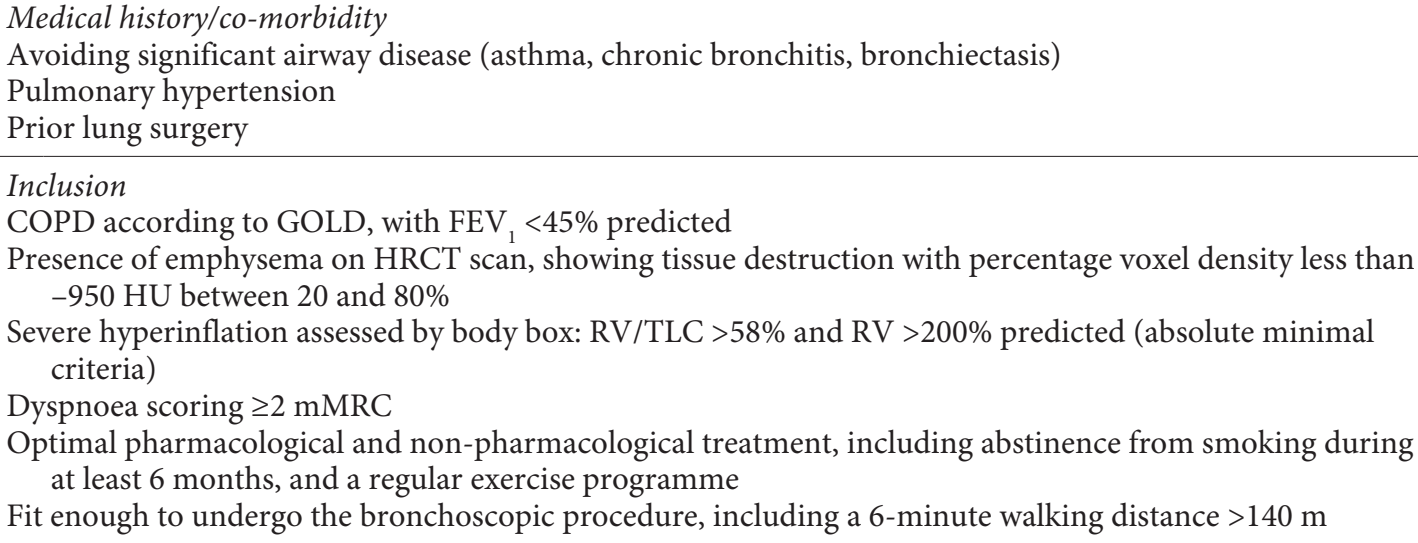
criteria)

Dyspnoea scoring $\geq 2 \mathrm{mMRC}$

Optimal pharmacological and non-pharmacological treatment, including abstinence from smoking during at least 6 months, and a regular exercise programme

Fit enough to undergo the bronchoscopic procedure, including a 6-minute walking distance $>140 \mathrm{~m}$

\section{Exclusion}

Severe gas exchange abnormality: $\mathrm{PaCO}_{2}>7.3 \mathrm{kPa}(55 \mathrm{~mm} \mathrm{Hg})$ and/or $\mathrm{PaO}_{2}<6.7 \mathrm{kPa}(50 \mathrm{~mm} \mathrm{Hg})$ (room air)

Recurrent airway infections $\geq 3$ times/year

Significant chronic bronchitis, including asthmatic bronchitis and Asthma COPD Overlap (ACO)

Radiological abnormalities like:

- Severe bronchial wall thickening

- Bronchiectasis

- Giant bullae $>1 / 3$ lung volume

- Significant presence of paraseptal emphysema

- Pulmonary nodules which are suspicious for lung cancer or active infection

- Significant fibrotic lesions and signs of interstitial lung disease

- Previous lung volume reduction surgery or lobectomy/pneumonectomy

Pulmonary hypertension defined by right ventricular systolic pressure $>50 \mathrm{~mm} \mathrm{Hg}$ via echocardiogram

Evidence of other disease(s) which may compromise survival of the subject or reduce the benefits of coil treatment

Medication like antiplatelet or anticoagulant therapy which cannot be stopped prior to the procedure

Chronic immunomodulatory therapy; e.g. methotrexate or anti-TNF to treat an autoimmune disorder, prednisolone $\geq 10 \mathrm{mg} /$ day, CVID (common variable immunodeficiency), maintenance antibiotics

Sensitivity or allergy to nickel or to drugs required to perform bronchoscopy
Endobronchial Coils for Endoscopic Lung Volume Reduction 


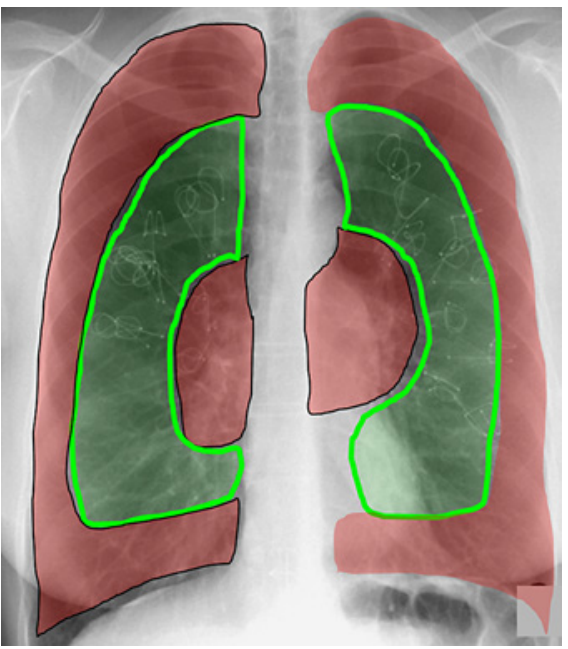

Fig. 4. Target area for coils. The ideal target area of coils is in the mid third of the lung; not too peripherally (the best distance to the pleura is $25-40 \mathrm{~mm}$ ) and not too centrally (not proximally of the segmental ostium).

\section{Coil Placement}

The lung volume reduction coil placement is preferably performed under general anaesthesia, and the patients are generally hospitalized for 1 night of observation following the procedure (this can vary widely with local practice, however). The coil procedure is a sequential treatment, with 1 lobe treated initially and the target lobe in the contralateral lung treated 4-8 weeks later. About 10-14 coils are placed in the target lobes under fluoroscopy (Fig. 2). The procedure is performed under fluoroscopic guidance.

First, the flexible guidewire, which has an atraumatic tip that serves as a guide for the delivery catheter, is used to identify suitable airways for treatment. It has radio opaque markers that correspond to the 3 different coil sizes and facilitate the choice of the appropriate coil length. The guidewire and catheter are inserted together into the instrument channel of the bronchoscope. The bronchoscope is advanced to the ostium of one of the sub-segmental airways in the treatment lobe (Fig. 3a). Afterwards, the guidewire is advanced into one of the sub-segmental airways and advanced as far as the pleura. This allows estimation of the target airway length. The wire is then withdrawn back from the pleural edge until a safe distance is guaranteed (best $25-40 \mathrm{~mm}$ ). The catheter is then gently advanced over the guidewire, again under fluoroscopy. In the majority of patients, it is only necessary to advance the catheter over the guidewire un- til just over one visible marker (Fig. 3b). This distance comfortably allows the placement of a 125 -mm length coil and ensures that wherever possible the coil is placed in the mid third of the lung and not in the periphery (Fig. 4). The catheter should not be advanced against resistance. Once the catheter has been advanced to the desired position, the guidewire is withdrawn until it is aligned with the catheter to measure the optimal coil size. The guidewire can then be withdrawn and the fluoroscopy switched off.

After loading the cartridge with the right sized coil, the cartridge is coupled with the catheter. The forceps and coil are then advanced through the catheter. A guide mark on the catheter advises the operator when the coil is approaching the distal end of the catheter, and the fluoroscopy should be recommenced at this stage. The coil is advanced until the ball and the first half loop of the coil are protruding from the catheter. This allows the coil to be anchored into position, and then the coil is deployed by withdrawing the catheter. As the coil is withdrawn, it reverts to its original shape, and once both the coil and the distal end of the grasping forceps are outside the catheter sheath, a small amount of reverse tension is placed on the grasping forceps, after which they are opened to release the coil: the coil will then jump out of the forceps (Fig. 5 shows all coil deployment steps). The coil placement process can be reversed to reposition or retrieve the coil, if necessary (Fig. 6). The authors believe that this is only necessary at max for 1 or 2 coils and best to be performed at the end of the procedure if a coil sticks out of the individual segmental or lobar airways. Fluoroscopy is again terminated after verifying that the coil has been appropriately deployed. The whole process is repeated until 10-12 coils have been deployed for upper lobe treatment and 10-14 coils for lower lobe treatment. The coils are preferably not placed in the segments RB4/5 and LB5 for safety reasons and lack of efficacy and safety data for these positions.

The absolute DON'Ts of this procedure are:

1. Use the catheter to push the guidewire forward or advancing the catheter distally beyond the guidewire (Fig. 7).

2. Advance the catheter against significant resistance.

3. Placing the coil too distally (outside ball within $25 \mathrm{~mm}$ of the pleura), or proximally (inside ball outside the segmental ostium).

4. Trying to release the coil by unlocking the forceps, while the forceps are still inside the catheter.

5. Placing 2 coils in the same segmental bronchus. 
Box 2. Step-by-step coil placement

1. Navigate the bronchoscope to the target airway and position at the ostium of a segmental airway.

2. Insert both the catheter and guidewire into the working channel of the bronchoscope.

3. Advance and navigate the guidewire into the distal targeted airway under fluoroscopy guidance.

4. Estimate position of pleural edge and length of the airway with the guidewire and then retract the guidewire so that it is either far enough from the pleural edge $(25-40 \mathrm{~mm})$ or a maximum of $1.25-1.5$ fluoroscopy markers distal from the tip of the bronchoscope (to accommodate a 125-mm coil).

5. Hold the guidewire position fixed relative to the bronchoscope and advance the catheter distally but not beyond the tip of the guidewire.

6. Once the catheter is in the desired position, withdraw the guidewire tip until it is aligned with the tip of the catheter.

7. Use the radiopaque markers on the guidewire to measure the airway length.

8. Remove the guidewire from the catheter while maintaining the catheter position.

9. The desired size coil can be loaded into the cartridge ( 1 radio-opaque marker or fractionally less = $100 \mathrm{~mm}$, at least more than $1.25-1.5$ of the distance between the first marker or more $=125 \mathrm{~mm}$, and if more than 2 markers consider using 150-mm coil).

10. Connect the cartridge to the Luer-lock hub of the catheter and lock into place.

11. Deliver the coil into the catheter by advancing the forceps and coil.

12. Align the distal end of the coil with the distal end of the catheter.

13. Position the coil using fluoroscopy.

14. Have an assistant hold the bronchoscope fixed relative to the patient.

15. Deploy the coil using fluoroscopy by withdrawing the catheter with one hand, while holding the coil position fixed with the forceps using the other hand.

16. Verify the position of the coil under fluoroscopy and release the coil by unlocking the forceps under gentle traction.

17. Remove the forceps from the catheter.

18. The catheter may continue to be used to repeat steps $2-17$ to deploy additional coils. The coil can be removed or repositioned by reversing this implantation process.

6. Losing the position of the tip of the catheter (by moving to a more central position) during the deployment phase of the coil.

7. Performing any of the coil placement steps without fluoroscopy.

\section{Patient Management and Bronchoscopy}

Patient management starts with selecting appropriate patients. A multi-disciplinary team (pulmonology, radiology, thoracic surgery and pulmonary rehabilitation knowledge) should be involved in selecting the most appropriate treatment for an individual patient. Frequently, pharmacological and non-pharmacological treatment need to be optimized, substantially delaying or preventing the start of a coil treatment. It is important to ensure that the patient is not a frequent exacerbator, particularly due to infectious bronchitis; hence, new patients may need to be monitored for a period prior to being considered for treatment.

Endobronchial Coils for Endoscopic Lung Volume Reduction
The patient should continue their routine medications. The procedure is best performed under general anaesthesia using local guidelines on both airway access (flexible endotracheal tube + positive pressure ventilation, or rigid bronchoscopy + jet ventilation) and anaesthetics used. Intubation with an un-cuffed endotracheal tube (Rusch or Portex) is recommended when the procedure is being performed under conscious sedation.

After introduction of the bronchoscope, the airways are inspected, and bronchial secretions are collected for microbial cultures. Coils are placed according to the stepby-step procedure described above. After disconnecting the forceps from a coil, leave the catheter in the entrance of the treated segmental bronchus, ready to support the next coil placement nearby that position, with as little manipulation as possible, in this way avoiding oedema, secretions, haemorrhage and bronchoconstriction. Sometimes, mild or moderate haemorrhage may occur, which mostly responds well to gentle suction. The procedure time varies between 20 and $45 \mathrm{~min}$ and a fluoroscopy time of 5-15 min, depending on patient factors, anaesthesia technique and physician experience with the technique. 

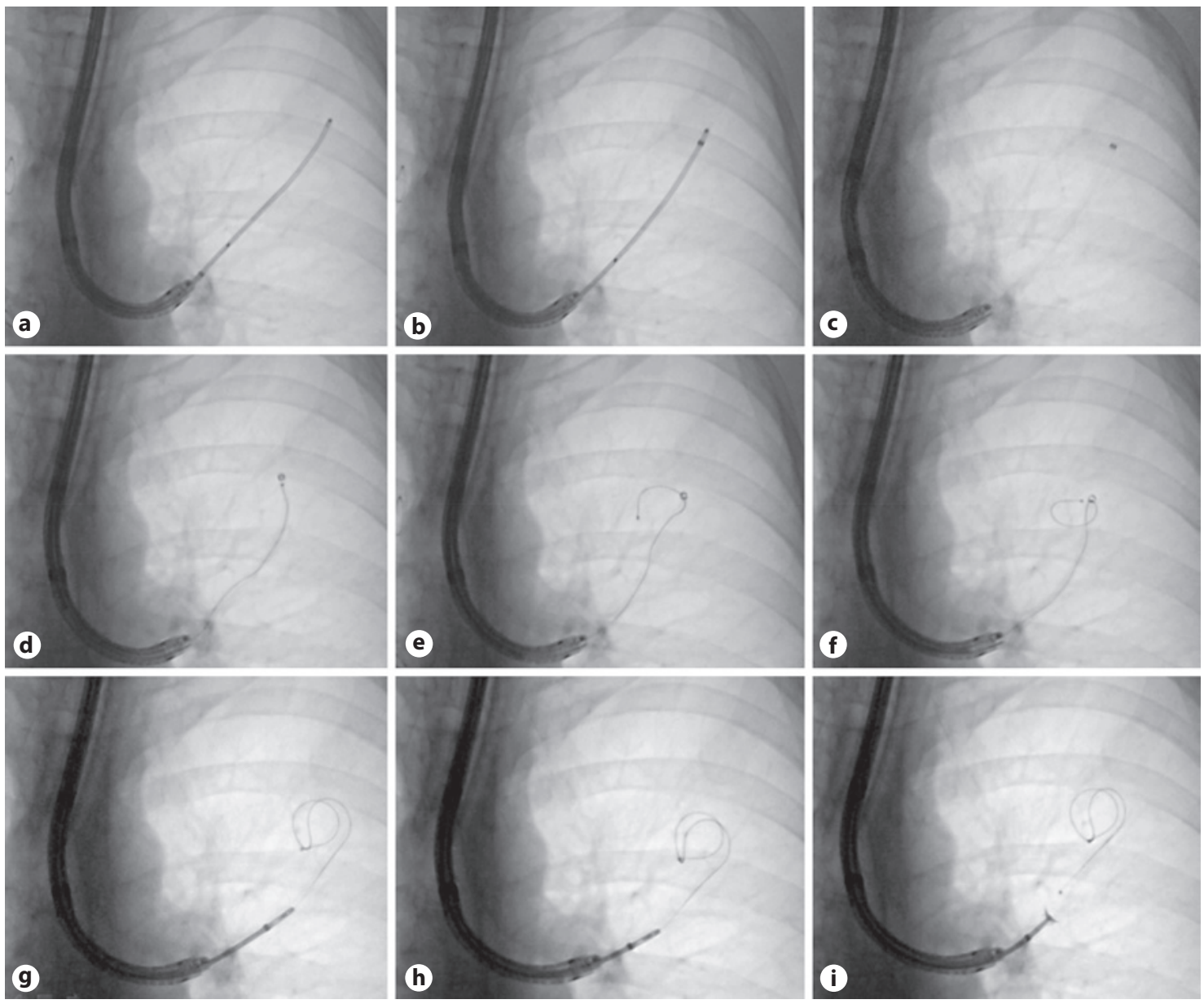

Fig. 5. Coil deployment. Fluoroscopic series of a coil placement in the left upper lobe. Note that the bronchoscope is positioned all the time at the same position at the ostium of the segment. a Introduction of the guidewire up to one marker plus $1 / 3$ length of the guidewire and 25-40 $\mathrm{mm}$ away from the pleura. Now, also the appropriate coil length can be chosen (in this case $125 \mathrm{~mm}$ ). b The catheter is advanced over the guidewire (which is held in a stable position) just up to the distal end of the guidewire. c The guidewire is removed, leaving the catheter in place with just a radio-opaque marker being visible at the distal end. d Introduction of the coil, which is being pushed forward using the biopsy forceps until it reaches the distal end (marker) of the catheter. e The coil is still

After extubation, the patient is stabilized routinely and monitored for vital functions in the recovery room for at least $2 \mathrm{~h}$. The patient is treated with at least 5 days of oral steroids and prophylactic antibiotics. The antibiotics can be adjusted according to bacterial sensitivities from previous cultures or the bronchial washings obtained during the procedure. A post-procedure chest radiograph should be performed both to record baseline coil position and to exclude a pneumothorax (very rare in experienced cen- being pushed forward until the first half loop of the coil has been deployed. f From this point, the catheter is withdrawn, keeping the coil in the exact position, which requires gentle feeding/pushing of the biopsy forceps in the distal direction. $\mathbf{g}$ The catheter is now fully withdrawn (allowing full coil deployment), also over the biopsy forceps head to allow release of the coil. $\mathbf{h}$ Gentle backward force is applied to both the catheter and biopsy forceps, thereby retracting the coil system about $2 \mathrm{~cm}$ back, also to facilitate coil release. $\mathbf{i}$ In this position, the biopsy forceps is opened, and the coil will jump out, back to the previous position. Repeat these steps for the next coils to be placed.

tres). If no complications have occurred, the patient is discharged from the hospital, with the second bronchoscopy being scheduled within 6-8 weeks.

\section{Adverse Events}

Adverse events generally occur in the peri-procedural and post-procedural period, and frequency returns to baseline in the months following the second procedure [11]. The RENEW trial reported a $15 \%$ excess incidence 

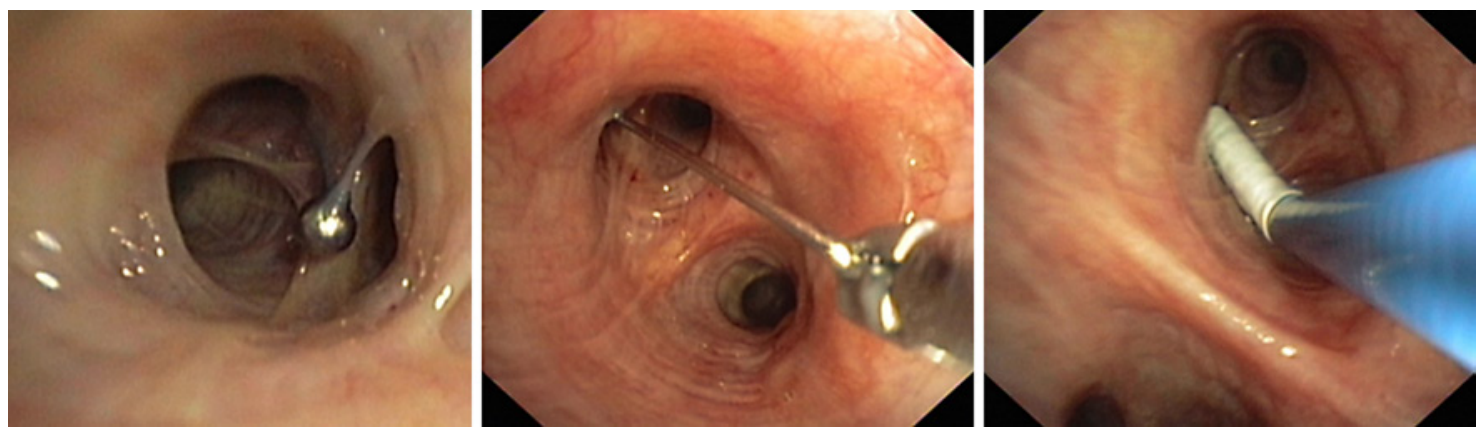

Fig. 6. Coil removal. The coil placement process can be reversed to reposition or retrieve the coil. First, grasp the proximal ball with the forceps. After aligning the forceps and coil by slight traction, the catheter can be gently advanced until the end of the coil but not distally from the coil. Afterwards, the coil and catheter can be withdrawn. Theoretically, the coil can be left at a more proximal position within the same retrieval procedure.

Fig. 7. Don'ts during the coil placement. The most important don't is to advance the catheter distally beyond the guidewire (left picture). The distal end of the catheter is too rigid and too sharp and may lead to haemorrhage and pneumothorax. Another important don't is to use the catheter to push the guidewire in front (right picture). Allow the guidewire to do the job of finding the right distal bronchi.

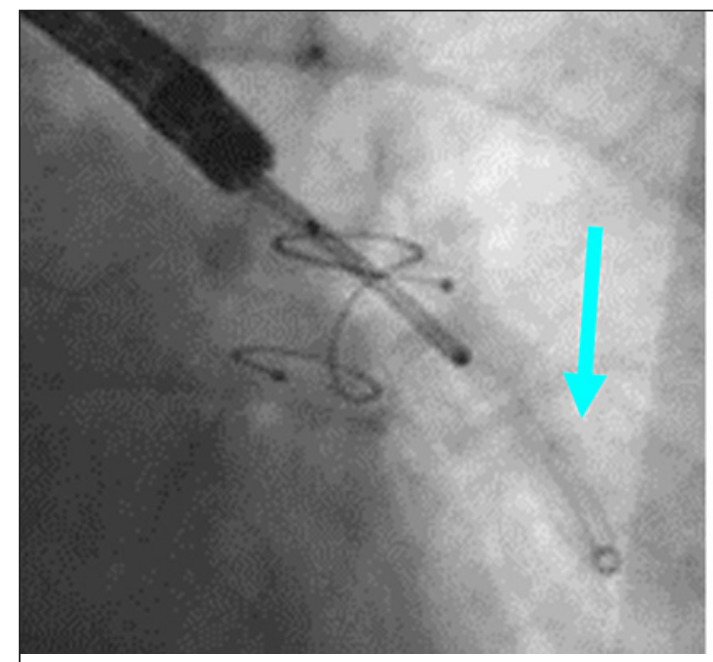

Do not advance the catheter without the guidewire in front

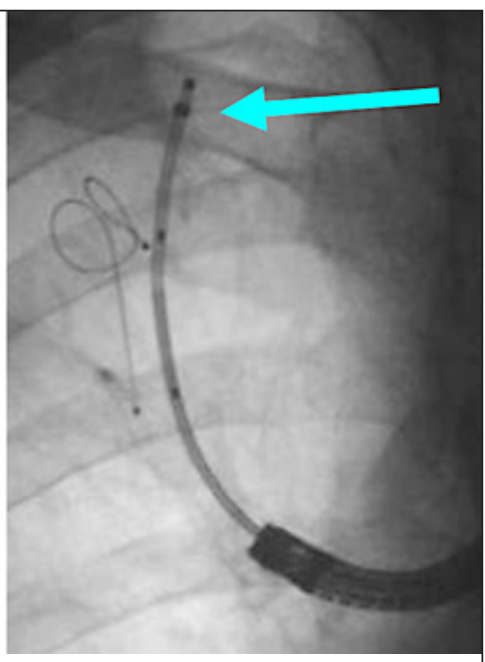

Do not use the catheter to push the guidewire forward of pneumonia in the coil versus usual care group, which is identical to earlier reports $[17,23]$. A number of these pneumonias appeared to be non-infectious in nature and are now considered secondary to the force of the coils on the lung tissue causing an inflammatory response. This response results in dense consolidations, mimicking an organizing pneumonia, and are referred to as "coil-associated opacity" (CAO) (Fig. 8). CAO thus behaves as a pneumonia, with chest discomfort, dyspnoea, low oxygen saturation, cough, elevated inflammatory markers and consolidations around some of the coils on a chest X-ray. Fever and purulent sputum are less prominent and may be absent. Patients should be treated for pneumonia, with the addition of oral corticosteroids $(0.5 \mathrm{mg} / \mathrm{kg})$. After re- covery, the patients who experienced a CAO normally are the best responders to the coil treatment due to significant reduction in treated lobar volume.

In the RENEW trial, there were 2 direct procedureassociated deaths; one patient died because of an intraprocedural pulmonary haemorrhage, and another patient died of respiratory failure 6 days following the second coil procedure [11]. In a 1-year single-centre retrospective analysis of 86 patients with severe COPD, totally 4 patients passed away within the first 3 months after the treatment due to complications [24]. All 4 patients suffered from severe pneumonia of the treated lung that was followed by sepsis and finally death; 2 of them also developed abscesses surrounding some of the coils, as was evi- 
Fig. 8. Coil-associated opacity. Coil-associated opacities are dense consolidations on the X-ray, mimicking an organizing pneumonia. On the left chest X-ray, the consolidations are in the left upper lobe, both proximally near the hill and distally extending to the pleura. On the right picture, the coil-associated opacities are larger and more dense. The coil-associated opacity in the left upper lobe shows also pleural involvement. Sometimes, an extra side view or computed tomography scanning is necessary to demonstrate the coil-associated position.
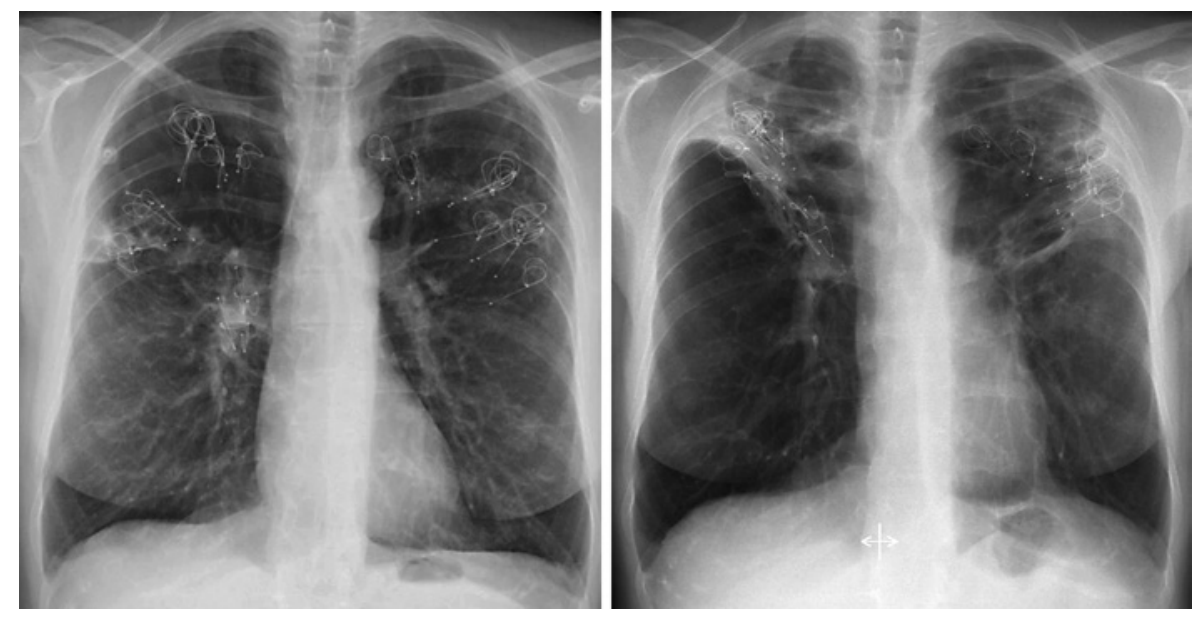

dent on CT. The authors suggested that we need to further elucidate possible aggravating factors and reduce the number of adverse events.

In this respect, we recommend the following precautions:

- careful selection of patients avoiding a high risk for respiratory infections;

- routine culture of bronchial secretions during the bronchoscopy procedure;

- a low threshold for collecting microbiological cultures of sputum, and starting antibiotics in case of potential respiratory infections after the coil placement;

- and a low threshold to admit patients to the hospital once complications after the coil placement seem to occur, and to instruct treated patients about this.

\section{Main Coil Procedure-Related Complications and Remarks}

- Pneumothorax 1-10\%: high reported occurrence in the RENEW trial (12\%); however, very uncommon in experienced sites (1\%) [11]. Treatment using regular pneumothorax guidelines. Video-assisted thoracic surgery might be necessary if caused by a pleural tear due to inadvertent distal coil placement.

- COPD exacerbations 10\%: can be managed by regular care.

- Pneumonia 10\%: can be managed by regular care, be aware of CAO occurrence.

- Minor haemoptysis 50\%: just post-procedure up to a few days after a tablespoon amount of haemoptysis might be produced, requiring no intervention. It is good to inform the patient about this.
- Major haemoptysis 1\%: has been reported after treatment in patients with pulmonary hypertension or maintenance anticoagulants (not aspirin). Management using local guidelines.

- CAO 10-50\%: very different incidence possibly due to a wide variety of coil placement techniques and patient selection. See above for treatment guidance.

- Avoid lung volume reduction coil treatment for patients with lifelong indications for systemic anticoagulants (except aspirin/ascal/carbasalate-calcium).

\section{Recommended Follow-Up after the Final Coil}

Placement

3 months post-procedure:

- mMRC, St George's Respiratory Questionnaire Response (SGRQ) or other

- Adverse events reporting

- Physical examination

- Chest X-ray

- Body box and spirometry post-bronchodilator

- Exercise testing 6 and 12 months post-procedure:

- mMRC, SGRQ or other

- Adverse events reporting

- Physical examination

- Chest X-ray

- Spirometry On indication:

- Sputum culture

- High-resolution CT scan Recommended:

- Yearly follow-up (also in shared-care models)

- Capture all data in registries/clinical trials 
Lung volume reduction coil treatment in severe emphysema

- has an acceptable safety profile in carefully selected patients, although special awareness has to be present for coil-associated opacity;

- is thought to reduce lung volume by compressing the most destructed areas of the lung parenchyma and to restore the lung elastic recoil; however, the exact mechanism of action still has to be elucidated;

- results in an improvement in pulmonary function, exercise performance and quality of life, particularly in patients with severe hyperinflation (RV > 200\% predicted) and heterogeneous emphysema;

- is also, but less, effective in lower-lobe predominant and homogeneous emphysema;

- is independent of collateral flow and does not sacrifice the treated area of gas exchange;

- patients should be managed in a dedicated multidisciplinary team.

\section{Disclosure Statement}

All authors treated patients in clinical trials, sponsored by PneumRx/BTG, USA. M.H., F.H., and P.S. treated patients with coils under regular care. All authors advised to PneumRx/BTG, USA.

\section{References}

1 van Geffen WH, Kerstjens HAM, Slebos DJ: Emerging bronchoscopic treatments for chronic obstructive pulmonary disease. Pharmacol Ther 2017;179:96-101.

2 Shah PL, Herth FJ, van Geffen WH, Deslee G, Slebos DJ: Lung volume reduction for emphysema. Lancet Respir Med 2017;5:147-156.

3 Slebos DJ, Hartman JE, Klooster K, Blaas S, Deslee G, Gesierich W, et al: Bronchoscopic coil treatment for patients with severe emphysema: a meta-analysis. Respiration 2015;90: 136-145.

4 Herth FJF, Slebos DJ, Criner GJ, Shah PL: Endoscopic lung volume reduction: an expert panel recommendation - update 2017. Respiration 2017;94:380-388.

5 Slebos DJ, Shah PL, Herth FJ, Valipour A: Endobronchial valves for endoscopic lung volume reduction: best practice recommendations from Expert Panel on Endoscopic Lung Volume Reduction. Respiration 2017;93: 138-150.

6 Klooster K, Ten Hacken NH, Hartman JE, Kerstjens HA, van Rikxoort EM, Slebos DJ: Endobronchial valves for emphysema without interlobar collateral ventilation. $\mathrm{N}$ Engl J Med 2015;373:2325-2335.

7 Vogelmeier CF, Criner GJ, Martinez FJ, Anzueto A, Barnes PJ, Bourbeau J, et al: Global strategy for the diagnosis, management, and prevention of chronic obstructive lung disease 2017 report. GOLD executive summary. Am J Respir Crit Care Med 2017;195:557-582.

8 Zoumot Z, Kemp SV, Singh S, Bicknell SR, McNulty WH, Hopkinson NS, et al: Endobronchial coils for severe emphysema are effective up to 12 months following treatment: medium term and cross-over results from a randomised controlled trial. PLoS One 2015;10:e0122656.

9 Slebos DJ, Klooster K, Ernst A, Herth FJF, Kerstjens HAM: Bronchoscopic lung volume reduction coil treatment of patients with se- vere heterogeneous emphysema. Chest 2012; 142:574-582.

10 Shah PL, Zoumot Z, Singh S, Bicknell SR, Ross ET, Quiring J, et al: Endobronchial coils for the treatment of severe emphysema with hyperinflation (RESET): a randomised controlled trial. Lancet Respir Med 2013;1:233-240.

11 Sciurba FC, Criner GJ, Strange C, Shah PL, Michaud G, Connolly TA, et al: Effect of endobronchial coils vs usual care on exercise tolerance in patients with severe emphysema: the RENEW randomized clinical trial. JAMA 2016;315:2178-2189.

12 Kontogianni K, Gerovasili V, Gompelmann D, Schuhmann M, Heussel CP, Herth FJ, et al: Effectiveness of endobronchial coil treatment for lung volume reduction in patients with severe heterogeneous emphysema and bilateral incomplete fissures: a six-month follow-up. Respiration 2014;88:52-60.

13 Klooster K, Ten Hacken NH, Franz I, Kerstjens HA, van Rikxoort EM, Slebos DJ: Lung volume reduction coil treatment in chronic obstructive pulmonary disease patients with homogeneous emphysema: a prospective feasibility trial. Respiration 2014;88:116-125.

14 Herth FJ, Eberhard R, Gompelmann D, Slebos DJ, Ernst A: Bronchoscopic lung volume reduction with a dedicated coil: a clinical pilot study. Ther Adv Respir Dis 2010;4:225-231.

15 Gulsen A, Sever F, Girgin P, Tamci NB, Yilmaz H: Evaluation of bronchoscopic lung volume reduction coil treatment results in patients with severe emphysema. Clin Respir J 2017;11:585-592.

16 Deslee G, Klooster K, Hetzel M, Stanzel F, Kessler R, Marquette $\mathrm{CH}$, et al: Lung volume reduction coil treatment for patients with severe emphysema: a European multicentre trial. Thorax 2014;69:980-986.

17 Deslee G, Mal H, Dutau H, Bourdin A, Vergnon JM, Pison C, et al: Lung volume reduc- tion coil treatment vs usual care in patients with severe emphysema: the REVOLENS randomized clinical trial. JAMA 2016;315:175184.

18 Klooster K, Ten Hacken NH, Slebos DJ: The lung volume reduction coil for the treatment of emphysema: a new therapy in development. Expert Rev Med Devices 2014;11:481489.

19 Kloth C, Thaiss WM, Hetzel J, Ditt H, Grosse U, Nikolaou K, et al: Impact of endobronchial coiling on segmental bronchial lumen in treated and untreated lung lobes: correlation with changes in lung volume, clinical and pulmonary function tests. Eur Radiol 2016;26: 2176-2183.

20 Palamidas AF, Kemp SV, Shen M, McNulty W, Zoumot Z, Hopkinson NS, et al: Putative mechanisms of action of endobronchial coils. Am J Respir Crit Care Med 2017;196:109-115.

21 Herth FJ, Slebos DJ, Rabe KF, Shah PL: Endoscopic lung volume reduction: an expert panel recommendation. Respiration 2016;91: 241-250.

22 Slebos DJ, Klooster K, Ten Hacken NH: Bronchoscopic lung volume reduction; in Hetzel M, Shah PL, Gompelmann D (eds): Interventional Pulmonology (ERS Monograph). Sheffield, European Respiratory Society, 2017, pp 276-293.

23 Hartman JE, Klooster K, Gortzak K, Ten Hacken NH, Slebos DJ: Long-term follow-up after bronchoscopic lung volume reduction treatment with coils in patients with severe emphysema. Respirology 2015;20:319-326.

24 Kontogianni K, Gerovasili V, Gompelmann D, Schuhmann M, Hoffmann H, Heussel CP, et al: Coil therapy for patients with severe emphysema and bilateral incomplete fissures - effectiveness and complications after 1-year follow-up: a single-center experience. Int $\mathrm{J}$ Chron $\mathrm{Ob}$ struct Pulmon Dis 2017;12:383-394. 